\title{
A correspondência poética de Max Martins e Age de Carvalho
}

The poetic correspondence of Max Martins and Age de Carvalho

\author{
Mayara Ribeiro GUIMARÃES* \\ Universidade Federal do Pará (UFPA)
}

\begin{abstract}
RESUMO: O ensaio visa apresentar um panorama da correspondência poética de Max Martins e Age de Carvalho, durante mais de vinte anos de amizade, ainda inédita ao público. Nela, estabelece-se uma aliança poética em que ambos se tornam leitores críticos do processo criativo um do outro. A partir da seleção de algumas cartas, trata de temas poéticos, registra o processo de escrita de A fala entre parêntesis (1982) e dá notícia da relação de amizade entre dois dos poetas de grande destaque da poesia paraense do século XX.
\end{abstract}

PALAVRAS-CHAVES: Max Martins. Age de Carvalho. Correspondência poética. Amizade.

ABSTRACT: This text aims at presenting an overview of the poetic correspondence of Max Martins and Age de Carvalho, still unpublished, for a period of over two decades of friendship. In the letters here presented, a poetic aliance is established and, from that, both poets become critics of each other, interfering and commenting the creative process of one another. By analysing some of the letters, this text discusses certain poetic themes, the creative process of $A$ fala entre parêntesis (1982) and the relationship between two of the greatest poets from the north of Brazil, in the XXth century.

KEYWORDS: Max Martins. Age de Carvalho. Poetic correspondence. Friendship.

Recebido em 13 de dezembro de 2016. Aprovado em 15 de dezembro de 2016.

\footnotetext{
* Mayara Ribeiro Guimarães é professora do Programa de Pós-Graduação em Letras da UFPA, Belém, Pará, e doutora em Literatura Brasileira pela UFRJ. E-mail: mayribeiro@uol.com.br.
} 


\section{Introdução}

Este ensaio é o primeiro anúncio de uma pesquisa que se inicia em torno da correspondência dos poetas paraenses Max Martins e Age de Carvalho, vinculada ao acervo pessoal deste último ${ }^{1}$. Nele, há uma estimativa de centenas de documentos, ainda em processo de organização e classificação, entre cartas, cartões postais, fotocópias de colagens e cadernetas de Max Martins, diários de viagem de Age de Carvalho, fotografias, recortes de jornais e revistas, desenhos, fotocópia de textos críticos e poemas de autores variados, documentos pessoais. As cartas apresentam um conteúdo variado de temas e assuntos privilegiados pelos poetas, desde livros lidos, notícias da vida em Belém e no Brasil nas décadas de 80 e 90, e da vida em território estrangeiro, até a confecção de poemas inteiros, ou fragmentos, traduções e reflexões sobre literatura.

Nelas, nota-se, de imediato, a reflexão sobre poesia, criação e escrita, muitas vezes ensejada pela discussão de obras e autores lidos por ambos, ou individualmente, tornados muitas vezes temas poéticos, além da intensificação do processo de escrita e da publicação de livros durante o período de correspondência. Dentre estes, estão A fala entre parêntesis, Arena, areia, Pedra-Um, Caveira 41, de Age, e 60/35, Para ter onde ir, Não para consolar, Colmando a lacuna, de Max, produções claramente afetadas pelo estímulo criativo do diálogo estabelecido entre os amigos. O que venho apresentar neste ensaio é mais um breve panorama da experiência poética e pessoal registrada nesta correspondência, tão extensa e ainda inédita, e menos uma leitura crítica detida em temas, seguido da apresentação de algumas cartas selecionadas.

\section{A década de 80}

Desde 1980, quando se iniciou a amizade entre os poetas, Max Martins e Age de Carvalho trocaram cartas em regime semanal, às vezes diário. Durante os anos de residência em Belém, a correspondência registra o método de escrita do projeto de $A$

\footnotetext{
${ }^{1}$ Age de Carvalho reside na Europa há mais de trinta anos. Durante esse período, correspondeu-se não apenas com Max Martins, mas outros intelectuais e poetas brasileiros. Entre eles, Benedito Nunes, Haroldo Maranhão, Laís Corrêa de Araújo, e, mais recentemente, André Vallias, entre outros. Seu acervo pessoal contém documentos que incluem uma correspondência que abrange os mais de vinte anos de correspondência com Max Martins.
} 
Fala entre parêntesis (1982), revelando o sistema compositivo da obra. E pelos 23 anos seguintes marcará o afastamento físico entre os poetas, com a saída de Age rumo à Europa, registrando o adensamento do elo entre amizade e poesia, numa aliança poética de leitores críticos dos processos criativos um do outro, em curso a partir de então.

De 1980 a 1982, ano em que A fala entre parêntesis é publicada, a correspondência é marcada por uma relação de mestre e discípulo, que gradativamente se transforma em um diálogo entre amigos, pares literários e leitores críticos, apagando a diferença geracional através da identificação existencial e estética descoberta pelos companheiros. Escrito a duas mãos, à maneira do poema comunitário, muito popular no Japão - a renga - a construção do livro está registrada em uma troca interminável de bilhetes, cartas, anotações em papéis avulsos, entregues pelo correio ou pessoalmente no trabalho ou na casa de cada um dos poetas, e encontra-se na íntegra, recolhido no acervo. Ali, notam-se as múltiplas etapas de elaboração dos fragmentos, em suas várias versões, que nascem sem uma ordem expressa e vão gradativamente encontrando sua orgânica ordenação.

Exemplo disso são as cartas datadas de 20 e 26 de fevereiro de 1981. A primeira traz apenas o fragmento, ainda incompleto, do que seria, naquele momento, o poema de número 2 e que, na edição final, é ordenado como número 6, onde se lê:

Já não há mais sonhos (lá) e amamos rastros brechas no asfalto onde se arrasta a asa resto (que cito e ex-cito, excita-me entre parênteses). 
Figura 1: Carta de Max Martins a Age de Carvalho, 20 de fevereiro de 1981.

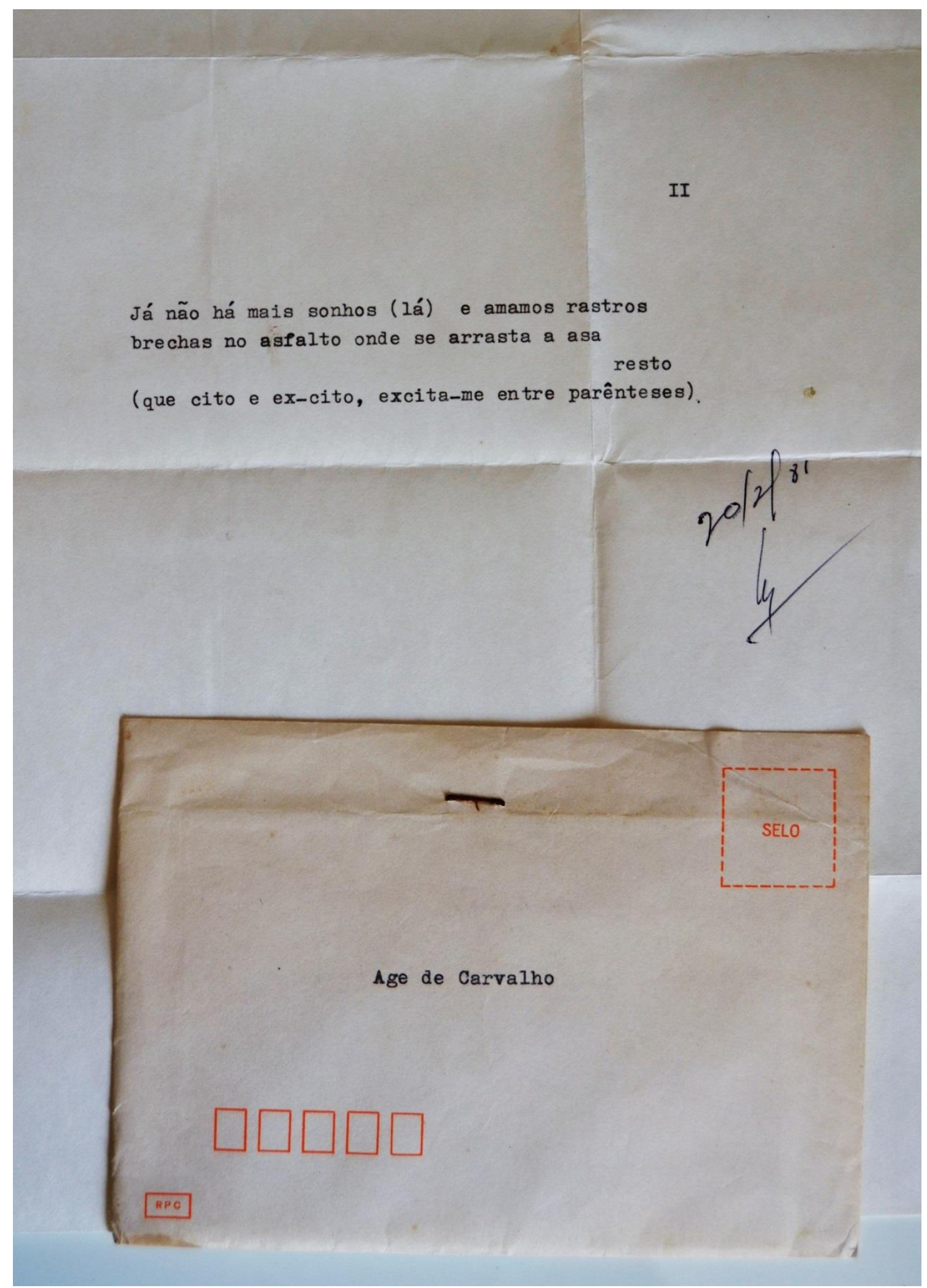

Fonte: Acervo particular de Age de Carvalho. 
A carta do dia 26, enviada de Marabá, contém a versão já completa no verso do papel.

Figura 2: Carta de Max Martins a Age de Carvalho, 26 de fevereiro de 1981.

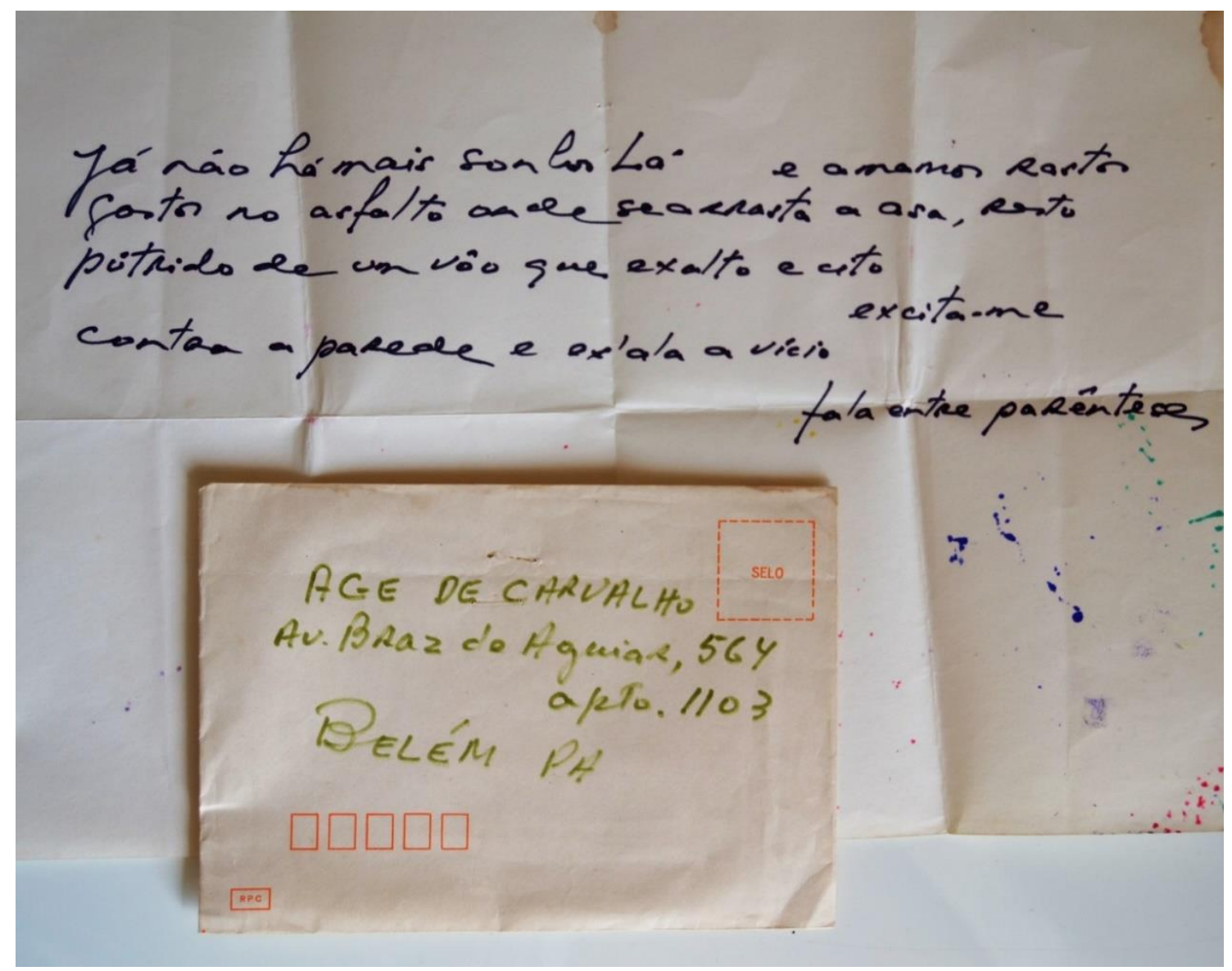

Fonte: Acervo particular de Age de Carvalho.

Uma curiosidade é a carta de 27 de julho de 1981 em que aparece, datilografado, o poema que seria o de número 12 , contendo um verso isolado, onde se lê: "eróticoerosivo o ideograma da morte" e a observação de Max: "um verso, uma imagem solta e disponível, pedindo poema". 
Figura 3: Carta de Max Martins a Age de Carvalho, 25 de julho de 1981.

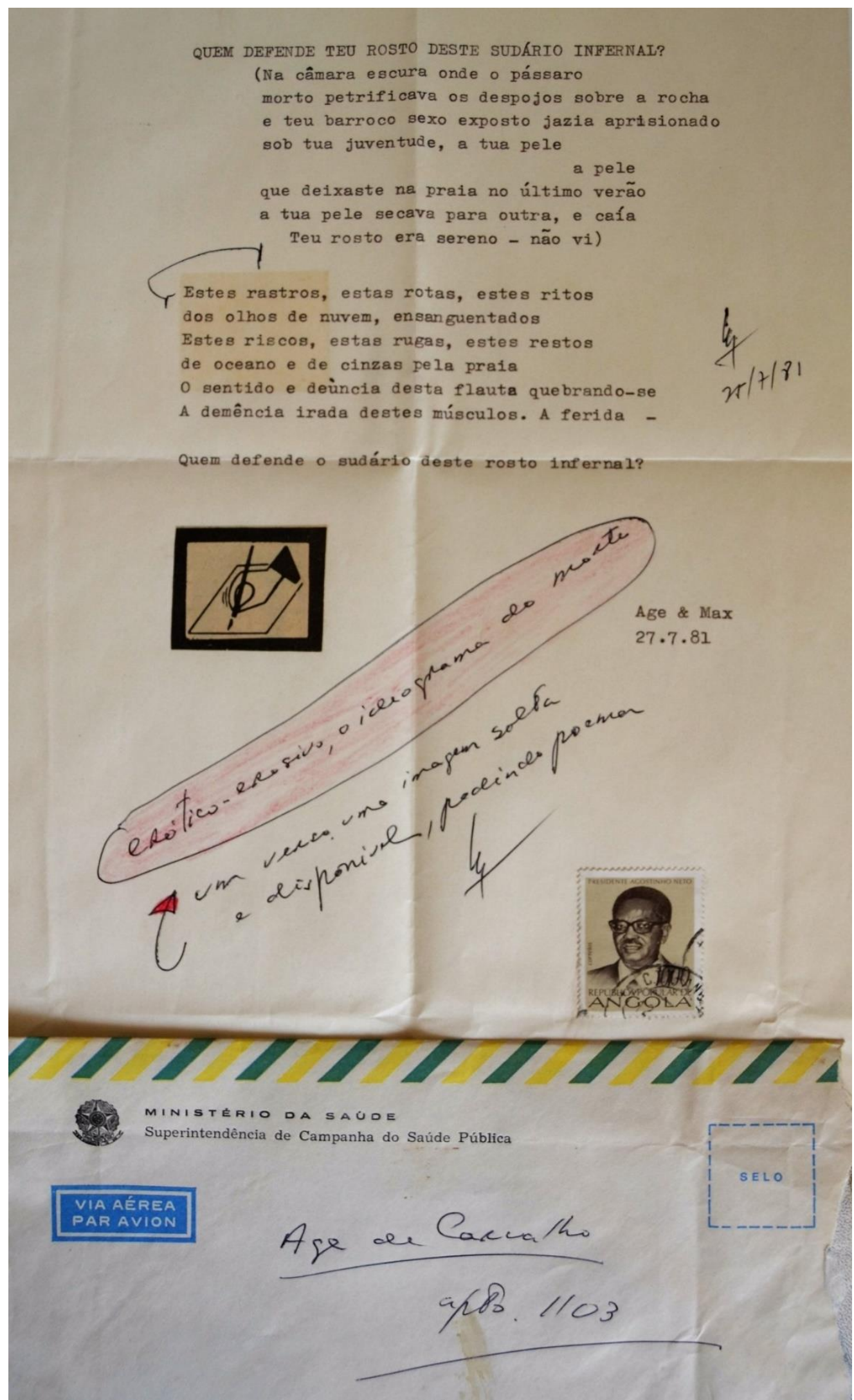

Fonte: Acervo particular de Age de Carvalho. 
Posteriormente, este verso fará parte do fragmento escrito por Max no poema de número 14:

em linho corrompido amordaçando a ilha amordaçando a chaga, aliciando a carne anavalhada, a lua negra na pele - eis erótico-erosivo, o ideograma da morte a flor da areia

A carta de 10 de agosto de 1981 mostra o registro deste mesmo poema, já contendo três dos quatro fragmentos, incluindo o trecho citado acima e o primeiro dos fragmentos que abrem o poema, acompanhado de um breve comentário galhofeiro, bem-humorado e atento a todo tipo de estímulo - artístico ou não - que possa contribuir para a confecção da escrita poética e tão característico da correspondência de ambos os autores.

A correspondência desses anos registra também os lançamentos do livro em Belém e no Rio de Janeiro e a repercussão e recepção da obra pela comunidade de leitores.

\section{Correspondências poéticas}

Como inspiração para a leitura de parte das cartas e preparação deste breve ensaio, busquei apoio no extenso volume de cartas trocadas por Carlos Drummond de Andrade e Mário de Andrade, organizadas pelo próprio Drummond e comentadas por Silviano Santiago. Em sua apresentação, Santiago chama atenção para o fato de que o leitor está acostumado a interpretar Drummond e Mário por meio de textos que, por decisão dos próprios autores, se tornaram públicos. Textos em que a experiência pessoal e íntima é dramatizada por meio da estilização literária dada pelo autor, alçando-a à condição de literatura, que, quando publicada, se torna universal.

Já a leitura de cartas que não foram endereçadas ao leitor e ao público, e que, portanto, restam íntimas e privadas, resulta em experiência única. Por meio dessa experiência penetramos na intimidade de Mário e Drummond, e, agora, de Max Martins e Age de Carvalho, dois poetas centrais para as letras paraenses e para a literatura 
brasileira na segunda metade do século XX. Entretanto, esse acesso ao privado e particular não é feito sem antes passarmos por um "ritual vergonhoso" de violação da intimidade alheia, afirma Silviano, transgressores de um limiar que separa público e privado.

Felizmente, os que entramos na vida privada dos correspondentes "estamos tomados do fervor religioso, que alicerça nosso respeito e admiração pela obra literária que um e outro nos legaram" (SANTIAGO: 2002, p. 9). O mesmo pode ser dito para as cartas que ora trago à esta exposição. Ciente da falta de originalidade que incorro, ao recorrer ao texto de Silviano, porém inspirada pelo acerto de suas palavras, quando insiste que a carta "traz em si o desejo de um tète-a-tète em que o correspondente tornase o espelho do outro", sou levada à leitura de um curto e apropriado texto de Michel Foucault que serve bem ao propósito de iluminar o que a escrita epistolar traz de essencial para o enriquecimento da obra poética de Max e Age. Trata-se do ensaio "A escrita de si”, sugerido pelo próprio Santiago, em seu prefácio. Ali, discute-se, ainda que partindo de exemplos da antiguidade clássica e não da modernidade, a natureza e a prática da escrita de diários e da correspondência, o que nos serve de mote para pensar essa prática à luz de nosso tempo e dos poetas aqui estudados.

O essencial: a importância do exercício da escrita como operador de uma função etopoietica na aquisição de uma técnica. Essa técnica nada mais é do que "a escrita da vida em forma de poesia”, como dirá Max em uma de suas cartas. A escrita de diários ou caderneta de notas e a prática da correspondência, enquanto exercícios de escrita pessoal, eram práticas diárias tanto de Max, quanto de Age. Assim como os diários de notas servem de "matéria prima" para o envio de cartas, ou como "pronto-socorro da memória"2, a correspondência, destinada a um outro, dá lugar a um exercício de escrita pessoal. Há aí uma dupla função de leitura e escrita importante no intercâmbio do que Benedito Nunes chamou de "passagem do subjetivo ao intersubjetivo", em ensaio de apresentação do livro A fala entre parêntesis, e que presenciamos, a meu ver, tanto nos poemas da renga, quanto na correspondência entre os dois poetas.

\footnotetext{
${ }^{2}$ Essa expressão é mencionada por Max Martins na entrevista concedida ao Museu da Imagem e do Som, em Belém, em 1996, incluída aqui neste dossiê.
} 
Este exercício torna-se alimento para a sensibilidade e o espírito por meio de uma presença alheia que contribui diretamente para o cultivo da alma sobre si próprio. Max estimula o jovem Age a ler determinados poetas, a cultivar o gosto pela tradução e pela escrita paralela de diários/cadernetas, que estimulam a produção poética. Age, por sua vez, com sua própria prática da redação de diários e cadernetas de viagens, o envio de imagens e textos - fotografias, cartões postais, traduções - e o comentário detido de poemas de Max, enseja e estimula a produção poética de Max. Enquanto o jovem poeta aperfeiçoa sua técnica e vai lentamente abrindo-se ao contato com uma língua estrangeira, que pouco a pouco adentra e modifica a sua poesia, o poeta experiente abrese mais ao mundo, empreende viagens e publica com frequência jamais antes experimentada.

\section{Assuntos poéticos}

Ambos aconselham-se, consolam-se e influenciam-se mutuamente. Em carta de 29 de setembro de 1982, o conselho que serviria para a solidão experimentada durante a estadia de Age no Rio de Janeiro, será relembrado ainda algumas outras vezes nas décadas seguinte:

Para com essa saudade aí. Senão não te escrevo mais contando as corriqueiras coisas daqui. Trata é de me relatar as coisas daí. Põe a saudade no saco, transforma em poema, que isso dá gloria e futura biografia a caráter. Durante o dia, nas horas vazias, sai, vai pra rua ver gente. Adoro ver gente, vai às livrarias, lê livros inteiros, copias belos poemas para mim, como o do Goethe, traduzido pelo Haroldo de Campos. Dá uma volta de bonde, espia lá de cima dos velhos arcos da Lapa as formigas humanas vivendo esse Rio que é lindo. Ou sofrendo, dá no mesmo, que tudo para o poeta é lindo, poeticamente falando. (Max Martins, 29 de setembro de 1982).

Já em 1984, dessa vez passando temporada de um ano em Innsbruck, na Áustria, debruçado sobre o estudo da língua alemã, a saudade do amigo e da terra natal fazem retornar o desespero da solidão. Na carta de 22 de janeiro, é a solidão que dá o tom:

Nada a fazer neste domingo. Resolvi te escrever como se me sentisse enfastiado - como diz a Cunca - no meu apartamento da Braz de Aguiar e desse um pulo na tua casa para um papo, talvez tomar uma coca no Bar do Parque, ver banca de revista na 15 de Agosto. Ou, 
como naquele domingo, ir almoçar no restaurante árabe da Pe. Eutíquio. Enfim, para te dizer que esse papo de Europa não está com nada se não se tem alguém para dividir as surpresas. (...) Não sei, fico pensando que não sei aproveitar sozinho o que me aparece de bom. (...) Quero dividir. (...) Quero cumplicidade, segredo para dois ou uma raça inteira. (Age de Carvalho, 22 de janeiro de 1984).

Algumas das cartas de maior destaque neste ano datam de 12 e 31 de janeiro de 1984 e 8 de fevereiro. Na primeira, Age comenta o poema "1937-1983", de Arena, areia, onde aproxima Mário Faustino e T. S. Eliot em versos citados no poema e pede auxílio ao amigo na leitura do original. A resposta viria na carta de fevereiro, intitulada "A poesia e sua experiência de morte". Nela, Max comenta detalhadamente o poema de Age, e ressalva:

É importante que um poema nosso encontre um leitor que goste dele. Desse gosto. Mas, é importante também, de mim para ti, dizer que não gostei quando é o caso. E de ti para mim. Este eu achei um poema difícil no seu início. Ele requer mais de uma leitura para ser apanhado firme pelo gogó. O leitor terá que fincar muito bem a sua lança no poema. (Max Martins, 8 de fevereiro de 1984). 
Figura 4: Carta de Max Martins a Age de Carvalho, 8 de fevereiro de 1984.

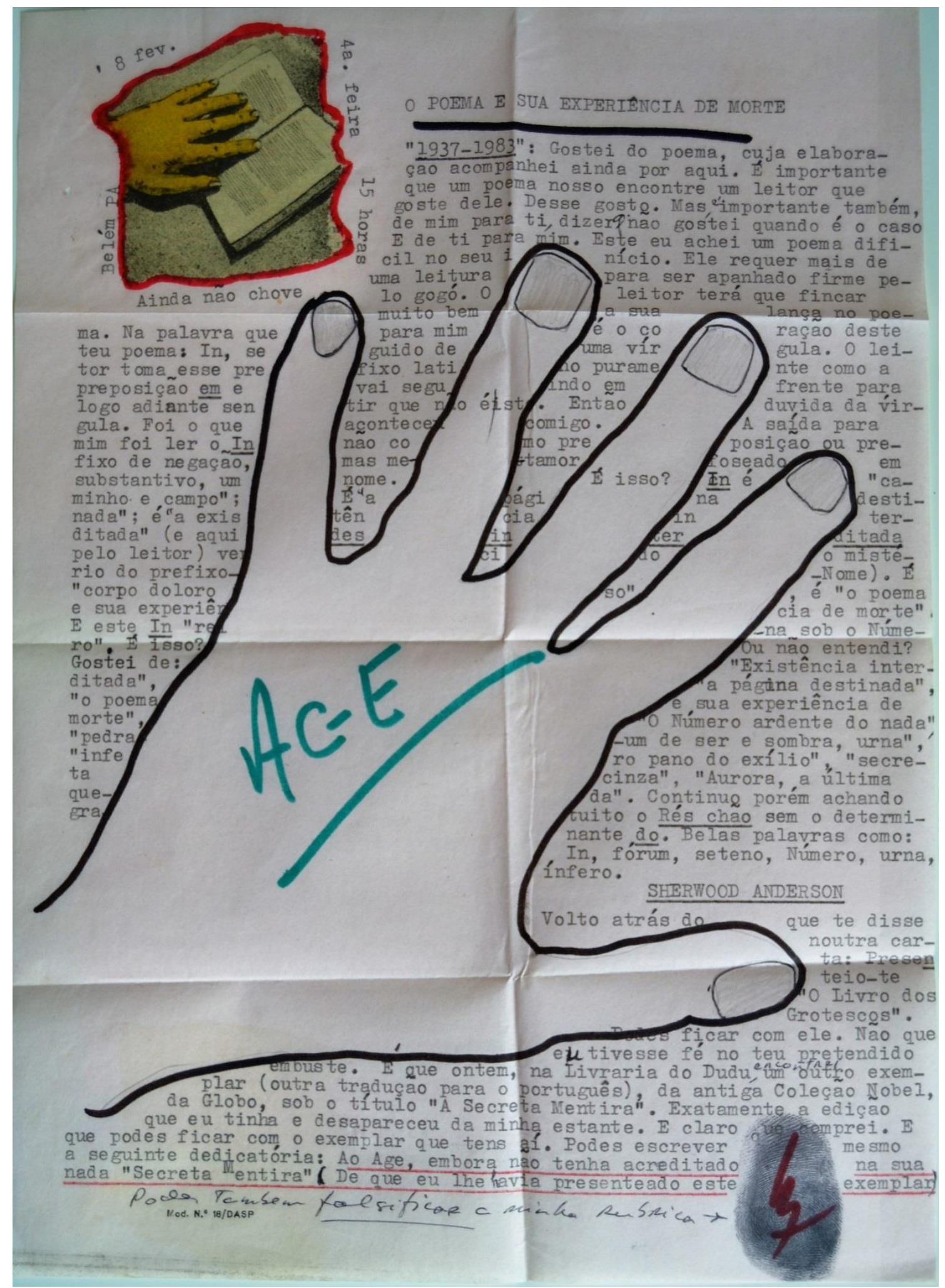

Fonte: Acervo particular de Age de Carvalho. 
E progride na análise, cuidadosa e certeira.

Mas é também nesta carta que Max comenta sobre o exercício tradutório, um dos temas presentes em toda a correspondência. Além de Edmond Jabès, Max traduz Henri Michaux, René Char, Francis Ponge, Blaise Cendrars, Juan Larrea, como afirma em carta datada de 27 de fevereiro. Na página Grápho, página de poesia e tradução editada por Age de Carvalho nos jornais Diário do Pará e O Liberal entre os anos de 1983 e 1985, algumas das traduções feitas por Max e pelo próprio Age aparecem publicadas. A tradução literária, para ambos, sempre foi exercício paralelo ao da própria escrita poética e de diários, E é justamente no livro Arena, areia (1986), de Age de Carvalho, do qual o poema "1937-1983" faz parte, que a tradução aparece como exercício paralelo à produção poética de Age.

Na carta datada de 8 de fevereiro de 1984, Max afirma:

Agora está liberada essa tradução de um dos poemas de Ponge. Com relação à minha poesia, por enquanto apenas penso muito nela. Não tenho escrito nada. Começada há uma tradução do Prosa Transiberiana de Blaise Cendrars. Também uma tradução parada dum pequeno poema de René Char. Ontem de noite traduzi um poema de Paul Celan (do francês, faltando conferir com o alemão do dicionário). (Max Martins, 8 de fevereiro de 1984).

E na de 31 de janeiro, comenta a edição da obra completa de Paul Celan, da Suhrkamp, adquirida por Age em Innsbruck, e incentiva o amigo no estudo da língua alemã:

Volto à Biblioteca, agora com a tua carta de 22/1 (...). Sim, dá água na boca (e remorso na língua de quem não sabe o alemão) a obra completa de Paul Celan da Suhrkamp. Ótimos os teus exercícios com o francês, o inglês, o alemão. Este, porém, acho eu, é o mais importante por vários motivos, bem sabes (...). E também, principalmente, para a leitura direta dos poetas que admiras, como o Celan, o Trakl. O dia que souberes bem o alemão, saberás também que estes poetas, seus poemas são outra coisa, para além do que as traduções mostram. É só pensar nos teus poemas em outra língua: serão os mesmos? Claro que não. Ótimo também quanto Às tuas leituras: Fernando Pessoa e Sherwood Anderson. O português vai te alimentar para sempre. Como o Drummond. Seus poemas marcam a gente, direcionalmente para sempre. Eles nos ajudam a pensar, sermos e vivermos. (Max Martins, 31 de janeiro de 1984).

Portanto, neste intercâmbio de cartas entre dois dos mais importantes poetas paraenses do século XX, revela-se também o compartilhamento de obsessões poéticas, 
visões políticas, e reflexões sobre o amor, a condição de imigrante, o envelhecimento, a doença e a morte, entre tantos outros assuntos.

\section{Não para consolar}

Benedito Nunes, na apresentação a A fala entre parêntesis, chama atenção para um dado que me parece central para a leitura desta correspondência. Se a renga se aproxima de um "simpoetar" apontado pelos românticos alemães do grupo de Jena, onde o jogo de criação entre os poetas suspende as "diferenças de expressões individuais" para fazer surgir "o idioma comum da intersubjetividade" no espaço poético, onde a renga se apresenta como uma "passagem do subjetivo ao intersubjetivo", não posso deixar de ler essas cartas como a extensão da conversação iniciada pelo jogo poético, agora continuada em missivas que interpolam a criação poética com a escrita pessoal.

Dois envelopes maciços servirão de exemplo a esse "simpoetar" e com eles finalizarei a minha breve exposição sobre essa extensa e bela correspondência poética. Trata-se, possivelmente, de duas das mais importantes cartas da correspondência de Max e Age. Nelas, Max faz um balanço de sua vida, de alma aberta e exposta, ao qual o amigo responde, em carta emocionada, estimulando-o e relembrando a trajetória do poeta.

O primeiro envelope, de 17 de outubro de 1992, contém um grupo de 45 folhas, escritas na forma de diário, que reproduzem o diário de Max Martins escrito ao longo de vários meses, ensejadas pelo aniversário de 66 anos e pela publicação de sua poesia reunida, na edição de Não para consolar, de 1992.

Iniciada e finalizada com dois autorretratos desenhados à mão, a carta abre e fecha, numa espécie de espiral, no dia de Finados, onde busca falar de si "para suprir o vácuo de notícias concretas." Conduzido por um guia - os diários, "cadernos de socorro à memória" - qual Dante pelo inferno e paraíso, é como se o poeta falasse de dentro do reino dos mortos. "Sou mais transparente no meu modo de ser, na relação pessoal (até com desconhecidos), do que escrevendo. Mas hoje, dia de Finados, encerro essa escrita toda." A única certeza, após a releitura incessante de sua poesia reunida, em Não para consolar e Para ter onde ir: a de que fez "uma dúzia de bons poemas. Eles, esses poucos poemas, são dignos de se ombrearem com os dos grandes poetas que 
conhecemos. Então não foi em vão". Dentro dessa certeza, uma afirmação e a relativização dessa mesma certeza: de que "só escrevi por amor, pela vida, pela comunhão total. Fiz do meu coração uma grande isca para fisgar o homem e tudo que é sensível no universo. Eis a minha religiosidade! Isso parece certeza. Não é tanto. Não pode ser." (Max Martins, 17 de outubro de 1992).

A carta inicia com a exaltação da vida e da poesia, e termina com a evocação da morte, como se nota no trecho abaixo:

Vida com a poesia. Foi com estes olhos (cegos-deslumbrados) que eu vi o mundo, os seres, o amor: com as palavras. Minha vida foi sempre o jogo com as metáforas. As palavras. Sedução para protegerem, do mundo, dos seres, do amor. Ilusão por ilusão!... Sim, amei a ilusão das palavras, mas na verdade também desconfiado delas. Do próprio mundo, dos seres, do amor. Um deleite esse deixar-me levar pelo amor, pelo mundo, pelos seres e principalmente pelas palavras. Mas com luta, uma guerra particular. E uma proposta: de ser com tudo. 1926, 1942, 1952 e 1992. Sessenta anos de vida, cinquenta de poesia, quarenta de publicação do primeiro livrinho, e os "poemas reunidos". A ilusão continuará a ser seguida? Ou predominará a desconfiança? Uma etapa? Outra etapa? razão diz que não mudarei. Feliz ou infelizmente? Feliz infelizmente. Estou meio cansado por dentro. E por fora, naturalmente. Procuro ficar quieto, esperar que os problemas, as preocupações, se dissolvam lá fora e aqui dentro de MIM (devia começar por não usar essas maiúsculas). Miller, zen-budismo, meus deuses-não-deuses ficarão para trás?

\section{(...)}

No último dia 20 de junho, abrindo um novo caderno-diário * (inaugurando o primeiro caderno dos que me mandaste pela Regina): "Estou com 66 anos. Não houve poema para o aniversário deste ano. Mas vale repetir aqui o verso do poema do ano passado: o semidestroçado frêmito de um destino cego de antemão. Minha poesia está ligada à minha vida. É biográfica, conto e canto o meu rastejar sobre a terra, bicho enluarado, animal de um deus, ou - a sua perda a cada assalto." Naquele 20 de junho, no teu telefonema, disseste-me, preocupado com o meu baixo astral, que relesse meu Henry Miller: reli. Meus amigos é que me conservaram vivo. Valeu. Emocionante também a tua carta sob o meu aniversário (está colada numa página do diário - que hoje vou relendo agora, recapitulando fatos registrados e que vão acompanhando a escritura desta carta.

Dias depois, depois da homenagem da Biblioteca do Estado, no dia 23, chegou a primeira remessa de exemplares do Para ter onde ir. $\mathrm{O}$ livro ficou muito bonito. Sobressaindo o projeto gráfico do Age, as fotos do Bela Borsodi e a composição da Martina. (Max Martins, 17 de outubro de 1992). 
Figura 5: Carta de Max Martins a Age de Carvalho, 17 de outubro de 1992.

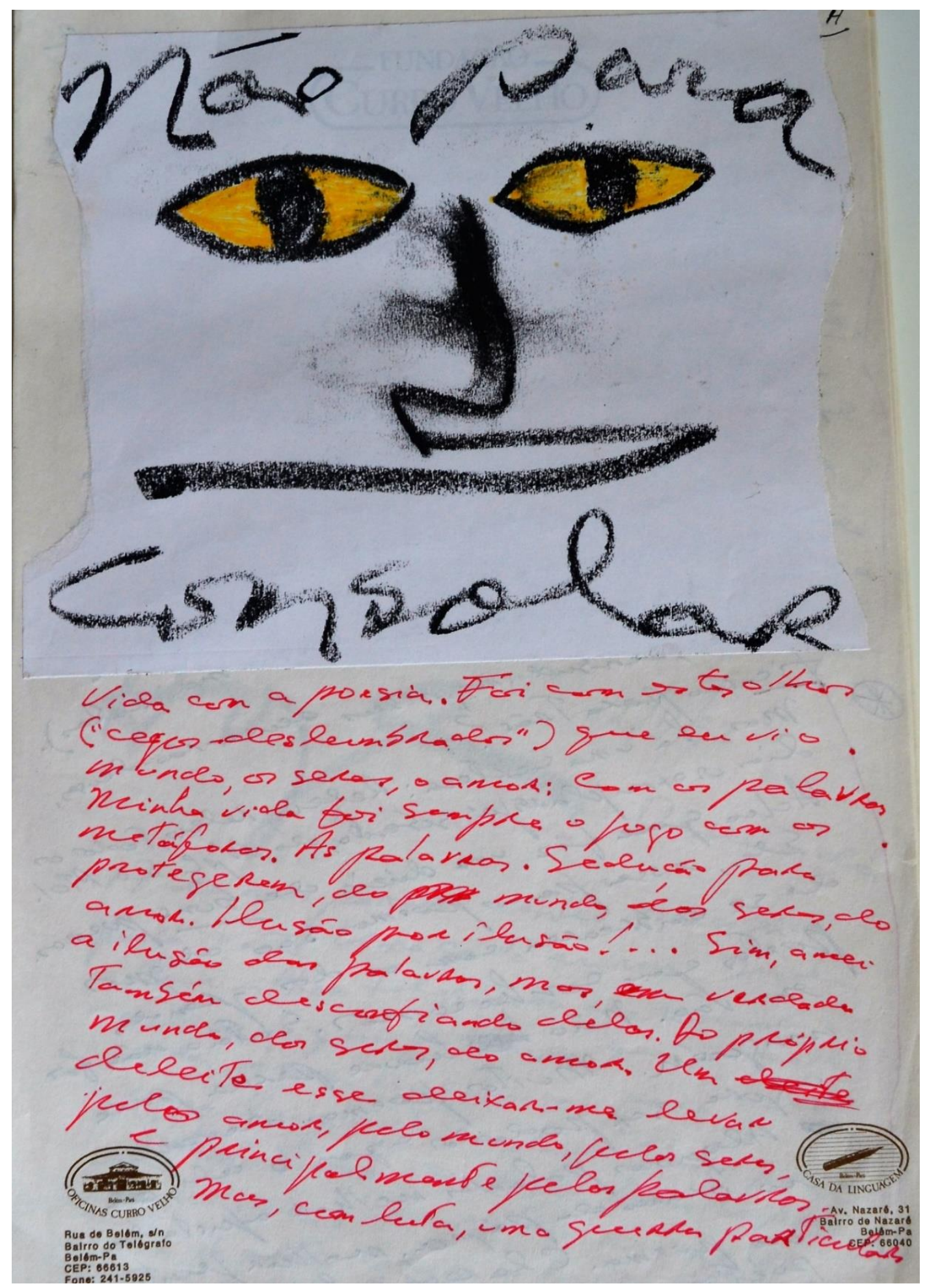

Fonte: Acervo particular de Age de Carvalho.

A carta continua, relatando uma série de acontecimentos sucessivos em dias variados do mês, que marcam a narrativa de Max. O poeta, então, passa a elaborar uma 
longa colagem de textos, diferenciados em preto e vermelho, que congregam vozes, às vezes separadas por aspas e nomeadas, às vezes não, intercaladas com sua voz pessoal, em relato com alta carga emotiva, de alguém que põe em revisão a vida, as perspectivas, o passado, o presente, o futuro e a escrita:

23/06: No Diário do Pará, reportagem de Reyvaldo Viñas: "Um poeta soletrado". Nesse dia, soube da morte do grande amigo da década de 50 - Max Budin. E Marcia me escreve num postal de Kokoschka: O amor é mais do que necessário. E a revista "Testo a fronte", de Milão, publica "Il calderone", na tradução do Sergio Wax... e recebo o poema "Cantilena em junho para o poeta", homenagem do Jurandyr Bezerra ao meu aniversário - Dizes: Bela é a nossa amizade ... o maravilhoso produzido por um encontro...

30/06: um desenho e estas palavras: "o último abrigo", "resistência", "os últimos vestígios", "natureza".

01/07: foto de uma colagem , com outra frase de uma carta de Margaret: "O que se passa? Que silêncio é esse?" Palavras de Júlia: "que coisa linda essa vida que vai nos alternando, diferentes estados, tensões, junções, infernos". - Foto de Wol. Júlia: "Deixe que as palavras façam amor entre nós"”. Na Estrela: documentário sobre Chagall. Dar corpo ao suceder, diz Guimarães Rosa. - A vida disfarça? - Pobre tem de ter um triste amor à honestidade. O que é pra ser - são as palavras.

13/07: Carta para o Age. Foto de Age e Pedro.

14/07: Age e Martina casaram no dia 10. "Serias nosso padrinho, se estivesse aqui, o que tanto gostaríamos". (Max Martins, 17 de outubro de 1992).

Não posso estender-me mais. Mas a carta é um longo balanço, o coração a nu, aberto. Uma espécie de recolha, arquivamento desordenado de acontecimentos perto do coração, dos elementos e pessoas mais importantes, que revelam quase que o procedimento de uma colagem tirada diretamente do mais íntimo jorro inconsciente e desordenado, repetindo talvez a organização poética de uma renga pessoal, onde muitas vozes ensejam o exercício desta escrita particular. Os comentários, em forma de diário, percorrem os meses de junho, julho, agosto, setembro, outubro e novembro. As frases em vermelho, em sua maioria retiradas de outros autores, alçam-se, por vezes, como uma segunda voz da consciência do poeta, questionando a vida, ponderando a morte, em lamentos e confissões.

Entre os autores citados, Guimarães Rosa, Murilo Mendes, Santo Agostinho, Fernando Pessoa, Novalis, e o próprio Max, num intercalado solilóquio formado de vozes parentes. As últimas frases da carta acenam um acerto de contas com a poesia: 
Com a minha poesia quis seduzir as pessoas. E ponho sensualidade nas palavras dos poemas. Carrego-as de energia triste" e a evocação dos mortos, no último dia registrado pela carta: o dia de Finados. Nesse dia, a "colagem" revela o tom fúnebre deste balanço de vida, evocando a linhagem cronológica dos antepassados: "Colagem. Figura humana em cinzento e preto. E estes nomes: Eurico Martins, Solange, Gilberto, Marieta, José Ladislau da Rocha, Maria Antonio Fernandes (tetravó), Isabel Aranha da Rocha, etc. Meus mortos". Assinado, Max Martins. (idem).

Não por acaso, a longa carta termina com um desenho, onde a rasura e a sobreposição de cores, formas e traços, identificam um corpo rasurado que deixa ver apenas uma cabeça e a palavra-legenda em letras negras: "Sancho, retrato final de Max da Rocha Martins".

Figura 6: Carta de Max Martins a Age de Carvalho, 17 de outubro de 1992. 


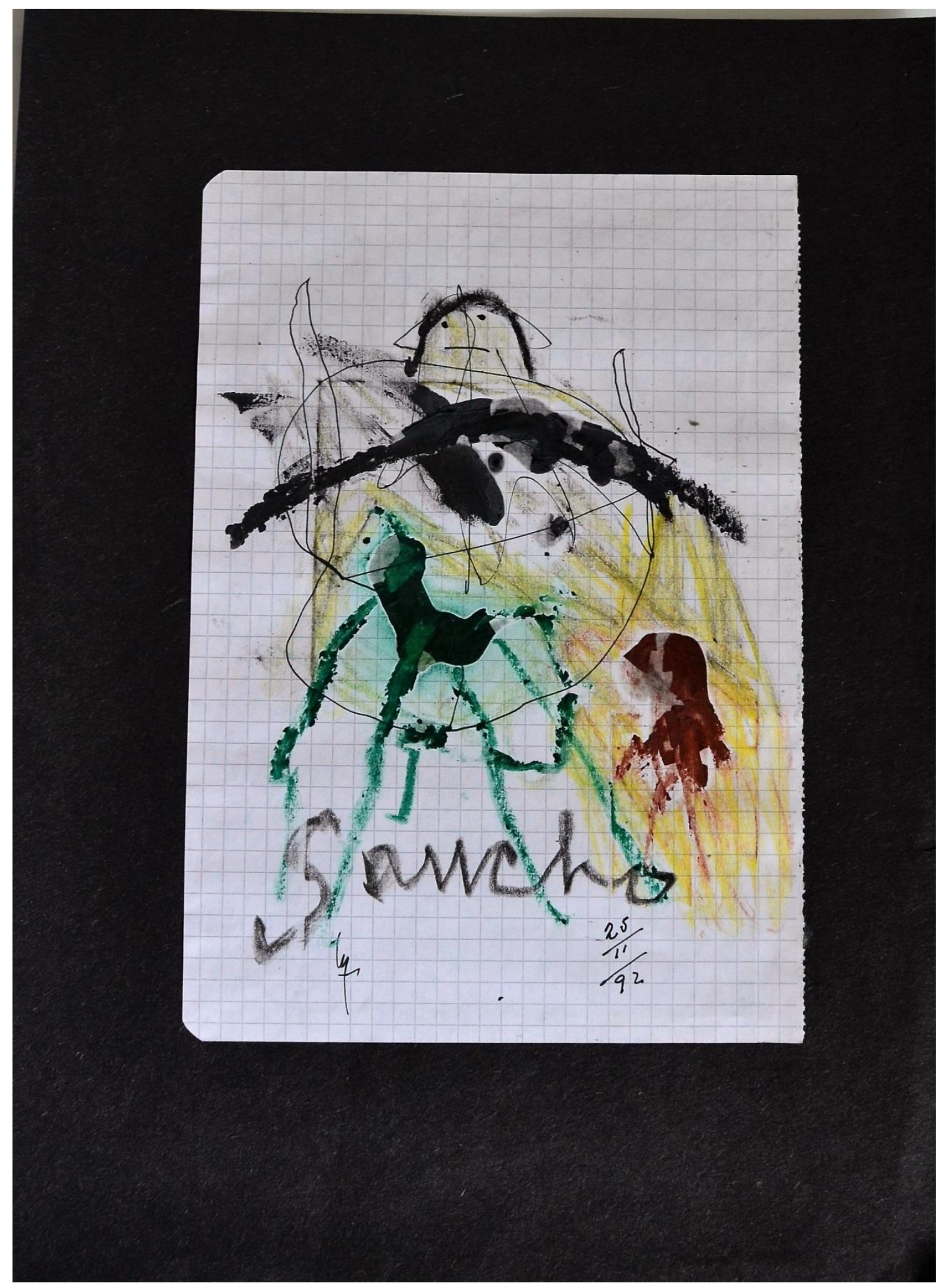

Fonte: Acervo particular de Age de Carvalho. 
Para finalizar, quero evocar as palavras de Age de Carvalho, em carta resposta ao amigo. Se a carta, tanto quanto o diário, é a busca de um diálogo consigo mesmo, o outro se torna um espelho e uma abertura "que o sujeito oferece ao outro sobre si".

O que dizer e por onde começar?

Recebo a carta-diário de 40 folhas, que chamar-se-á "Carta não para consolar", pois é com essas palavras que inicias a maravilha em letras imensas, negras, emoldurando um rosto, os olhos luminosos, teus, pelos quais viste "o mundo, os seres, o amor". Carta que move e comove, e comovido estou agora, tentando ganhar tempo para começar esta outra, sem saber bem o que dizer. E sinto a tua tristeza e não quero que penses tanto na morte e não quero que morras. E nem queres. Mas estás impressionado com isso. E sei um dos motivos: o lançamento das obras completas. Isso te fez olhar para trás, vê-se o lastro alcançado, e o veredito: "Estou meio cansado por dentro". Eu, quando vi o livro, os poemas todos ali reunidos, imaginei o que te passaria pela cabeça. Eu te conheço, somos amigos. Fizeste mais que uma dúzia de bons poemas e, sem falsas vaidades, sabes bem que podes ombrear-te com alguns dos teus poetas favoritos. Agradeço-te que não tenhas riscado este trecho da carta, como confessas num outro trecho mais adiante. Bem mais que uma dúzia de bons poemas. Isso é o que ficará. Tua dedicação à poesia, tuas intenções, os obstáculos e dificuldades, nada disso interessará posteriormente (talvez a alguns, amigos, eu entre eles). O resultado é o que conta, essa dúzia (bem mais) de poemas é o que fica. Sabes disso. Então? Então, deves saber também que tens cumprido o teu papel com a poesia, "então não foi em vão", então honras a tua arte. Então estás quites e podes deixar de lado certas perguntas e voltar à carga, aliviado (será possível?), aos novos poemas que virão. No final da tua carta, fazes a correta diagnose: "Só a poesia, um novo poema me tirará dessa situação desesperançada". Penso o mesmo: falta-te o mimo de uma cria nova. Alguma coisa falta ainda: justiça para contigo mesmo. Com todos os atributos com que te vejo, um, parece, não conseguiste alcançar até agora: saber julgar-se a si próprio, e quando o fazes é para desmerecer-te, rebaixar-te, jogar merda em ti mesmo. Acho que sabes disso. Carregas uma culpa que não sabes bem do quê nem por quem. Culpa por salvar-se? Mas a tua salvação não se fez às custas de ninguém. A tua salvação esteve sempre contigo, em ti estava e está, e é isso, me parece, o que te atormenta. Salvação pelo esclarecimento, o que alcançaste pela poesia. Mesmo quando duvidas, é o homem esclarecido que indaga, o mesmo que pode construir as redes dessa dúvida. (Age de Carvalho, 9 de novembro de 1992). 
Figura 7: Carta de Age de Carvalho a Max Martins, 9 de novembro de 1992.

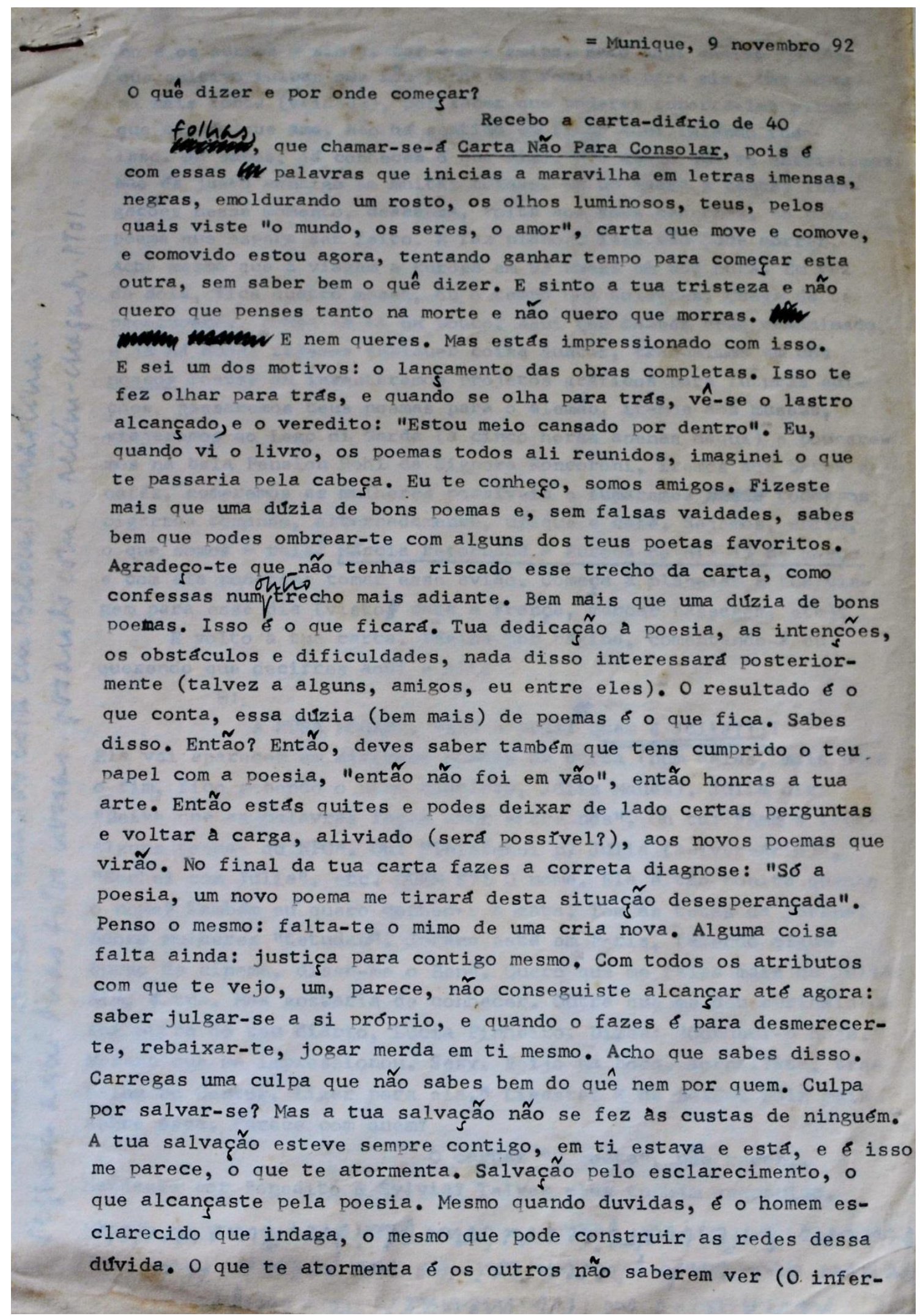

Fonte: Acervo particular de Age de Carvalho. 


\section{REFERÊNCIAS}

NUNES, Benedito. "Jogo marcado". In: A fala entre parêntesis, renga. Belém, Grafisa, 1982.

FOUCAULT, Michel. “A escrita de si”. In: O que é um autor? Lisboa: Passagens, 1992.

MARTINS, Max, CARVALHO, Age de. Correspondência poética inédita pertencente ao acervo particular de Age de Carvalho.

SANTIAGO, Silviano. "Prefácio". In: Carlos e Mário: correspondência entre Carlos Drummond de Andrade - inédita - e Mário de Andrade: 1924-1945. Rio de Janeiro:

Bem-te-vi Produções Literárias, 2002. 